\title{
Special issue of papers from the 7th European Conference on Precision Agriculture (ECPA)
}

\author{
Margaret A. Oliver · John Stafford
}

Published online: 20 June 2010

(C) Springer Science+Business Media, LLC 2010

The 7th European Conference on Precision Agriculture was held in Wageningen, The Netherlands in July 2009. The conference was one of three organized within a Joint International Agricultural Conference. Dr. Kees Lokhorst was the Chairperson for this conference. The conference attracted 487 participants from several academic disciplines within precision agriculture, precision livestock and information technology. There were 268 oral presentations and 135 poster presentations in the 64 sessions. It is from the oral presentations that the six papers in this special issue have been expanded into papers suitable for the Journal. Each paper has been reviewed by at least two reviewers before being accepted for publication.

Although the six papers in the special issue cover a range of topics, sensing of one form or another features in them all. The first two papers are based explicitly on remotely sensed data. The first uses the inversion of 1-D and 4-D canopy models to retrieve vegetation properties from remotely sensed data. Two contrasting types of radiative transfer models were assessed with multiple view angle data recorded from field experiments on maize at growth stages V5 to V8. The second paper evaluates vegetation indices from hyperspectral data to estimate nitrogen concentration in winter wheat at different growth stages. Three field experiments involved different winter wheat cultivars and 4-6 rates of nitrogen. The first paper on viticulture uses a model to predict the spatial variation in the water status of vines in SW France using high resolution ancillary data. The latter included airborne imagery and apparent soil electrical resistivity. Predictions from the model are compared with field measured water status. The second paper on viticulture uses a technical opportunity index based on fuzzy logic to assess whether the spatial variation in a field is suitable for variable-rate application in relation to the footprint of the machinery used for the applications. The fifth paper is both fascinating and unusual. It illustrates the increasing

\section{A. Oliver $(\square)$}

Department of Soil Science, University of Reading, Whiteknights,

P.O. Box 233, Reading RG6 6DW, UK

e-mail: m.a.oliver@reading.ac.uk

J. Stafford

Silsoe Solutions, Ampthill, Bedford, UK

e-mail: john.stafford@silsoe-solutions.co.uk 
diversity of precision agriculture and in particular its importance in crops of high value. The tulip breaking virus causes losses of the tulip crop because infected plants have to be removed from the field as soon as possible. Four proximal optical sensing techniques are applied to detect the virus and compared with a visual assessment by crop experts and also an enzyme immunoassay analysis of the same plants. The final paper is also concerned with disease detection - of three specific fungal diseases of sugar beet. Hyper-spectral reflectance data were used in spectral vegetation indices to discriminate the diseases. Although only a laboratory study at this stage, results were sufficiently encouraging to consider application in the field. 